\title{
Overexpression of hypoxia-inducible factor and metabolic pathways: possible targets of cancer
}

\author{
Davinder Singh ${ }^{1}$, Rohit Arora ${ }^{2}$, Pardeep Kaur ${ }^{1}$, Balbir Singh ${ }^{3}$, Rahul Mannan ${ }^{4}$ and Saroj Arora ${ }^{* *}$
}

\begin{abstract}
Cancer, the main cause of human deaths in the modern world is a group of diseases. Anticancer drug discovery is a challenge for scientists because of involvement of multiple survival pathways of cancer cells. An extensive study on the regulation of each step of these pathways may help find a potential cancer target. Up-regulated HIF-1 expression and altered metabolic pathways are two classical characteristics of cancer. Oxygen-dependent (through pVHL, PHDs, calcium-mediated) and independent (through growth factor signaling pathway, mdm2 pathway, HSP90) regulation of HIF-1 a leads to angiogenesis, metastasis, and cell survival. The two subunits of HIF-1 regulates in the same fashion through different mechanisms. HIF-1 a translation upregulates via mammalian target of rapamycin and mitogen-activated protein kinase signaling pathways, whereas HIF-1 $\beta$ through calmodulin kinase. Further, the stabilized interactions of these two subunits are important for proper functioning. Also, metabolic pathways crucial for the formation of building blocks (pentose phosphate pathway) and energy generation (glycolysis, TCA cycle and catabolism of glutamine) are altered in cancer cells to protect them from oxidative stress and to meet the reduced oxygen and nutrient supply. Up-regulated anaerobic metabolism occurs through enhanced expression of hexokinase, phosphofructokinase, triosephosphate isomerase, glucose 6-phosphate dehydrogenase and down-regulation of aerobic metabolism via pyruvate dehydrogenase kinase and lactate dehydrogenase which compensate energy requirements along with high glucose intake. Controlled expression of these two pathways through their common intermediate may serve as potent cancer target in future.
\end{abstract}

Keywords: mTOR signaling pathway, HIF-1a, Hypoxia, Metabolic pathways, p53, Glycolysis

\section{Background}

Cancer is a known worldwide threat responsible for $\sim 7.6$ million deaths per year, which is expected to reach 13.1 million by 2030 [1]. Cancer, a multifactorial disease is the second main cause of human deaths after cardiovascular diseases. Biological systems have various pathways to suppress cancer propagation such as tumor suppresser genes, cell cycle check points, DNA error repair system etc. Down regulation or malfunctioning of these system results in initiation of cancer. Over expression of hypoxia inducible factor (HIF) and altered metabolic pathways are

\footnotetext{
*Correspondence: dr.sarojarora@gmail.com; sarojarora.gndu@gmail.com 1 Department of Botanical and Environmental Sciences, Guru Nanak Dev University, Amritsar 143005, India

Full list of author information is available at the end of the article
}

two classical features of cancer [2]. HIF-1 is a transcription factor regulating many pivotal pathways in normal as well as cancerous cells. It is over expressed in organs or tissues where oxygen level drops below threshold level [3]. High level of HIF-1 points towards angiogenesis, cell proliferation, survival and tumor progression through regulation of growth promoters, oncogenes, glycolytic pathways and $\mathrm{pH}$ regulation. A large number of studies support the relation of increased level of HIF-1 with aggressive tumor growth and poor patient prognosis [4-8]. Metabolic pathways are crucial for growth and survival of cells. Intensively proliferating cells (as in cancer) needs high rate of energy and thus metabolic pathways are modified to match the need. The anaerobic condition results in drastic drop of energy production as lower number of ATPs are produced. Up-regulation 
of glycolysis and regulated feedback systems solve this problem. These two factors (HIF-1 and metabolic pathways) help cancer cells in rapid proliferation and also for angiogenesis, metastasis and evading apoptosis. This review is thus compiled to analyze the role of HIF-1 and altered metabolic regulation in cancer.

\section{Hypoxia-inducible factor}

\section{Structure}

HIF is a heterodimer protein consisting of two subunits, HIF- $\alpha$ and HIF- $\beta$. There are two other substitutes of HIF- $1 \alpha$ such as HIF- $2 \alpha$ and HIF- $3 \alpha[9,10]$. Both HIF- $1 \alpha$ and HIF- $2 \alpha$ have the ability to heterodimerize to HIF- $1 \beta$ subunit because of $85 \%$ sequence similarity in bHLH domain [11]. Expression of HIF- $\alpha$ subunit is oxygen dependent while HIF- $\beta$ constitutively expresses independent of oxygen level. HIF- $\beta$ subunit is also known as aryl hydrocarbon receptor nuclear translocator (ARNT) and binds to aryl hydrocarbon receptor (AhR) to promote its translocation to the nucleus [12]. Both HIF- $\alpha$ and HIF- $\beta$ subunits belong to bHLH-PAS (basic helix loop helix-Per ARNT Sim) protein family found in Drosophila [13]. All three HIF- $\alpha$ subunits contain oxygendependent degradation domain (ODD) and $\mathrm{N}$-terminal transactivational domain (N-TAD). In addition, HIF- $1 \alpha$ and HIF- $2 \alpha$ also contain a $\mathrm{C}$-terminal transactivational domain (C-TAD) [14], but HIF-1 $\beta$ lacks all regulatory regions (Fig. 1). The ODD domain is crucial for activity and stability of HIF- $\alpha$ subunits as it contains proline and asparagine for hydroxylation under normoxic conditions [15]. Some co-activators such as C-TAD binding protein (CBP) and P300 bind with C-TAD and regulate HIF expression by altering local chromatin structure through lysine acetyltransferase (KAT) activity and interaction with core transcriptional machinery [16].

\section{Functions}

Human tissues need ample supply of oxygen to maintain constant energy level through aerobic metabolic pathways. In some disorders such as cancer, chronic obstructive pulmonary disorders, ischemia or heart diseases, the oxygen level is drained, thus leading to hypoxic condition [17]. These conditions up-regulate HIF expression and down-regulate its degradation. HIF plays an important role in various cell signaling pathways besides three major roles, to regulate angiogenesis, metabolic pathways and $\mathrm{pH}$ (Fig. 2). Hypoxia is mainly common in solid tumors, where cells proliferate very fast, resulting in compression of blood vessels. To compensate this problem,

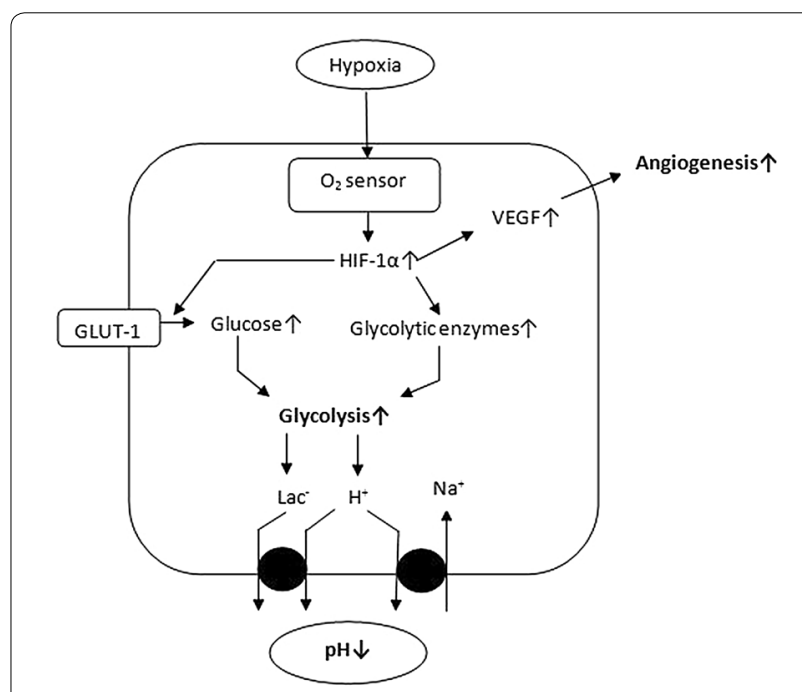

Fig. 2 Major roles of HIF-1; regulation of angiogenesis through VEGF, $\mathrm{pH}$ through sodium hydrogen pumps and glycolysis through glycolytic enzymes as well as glucose transporters

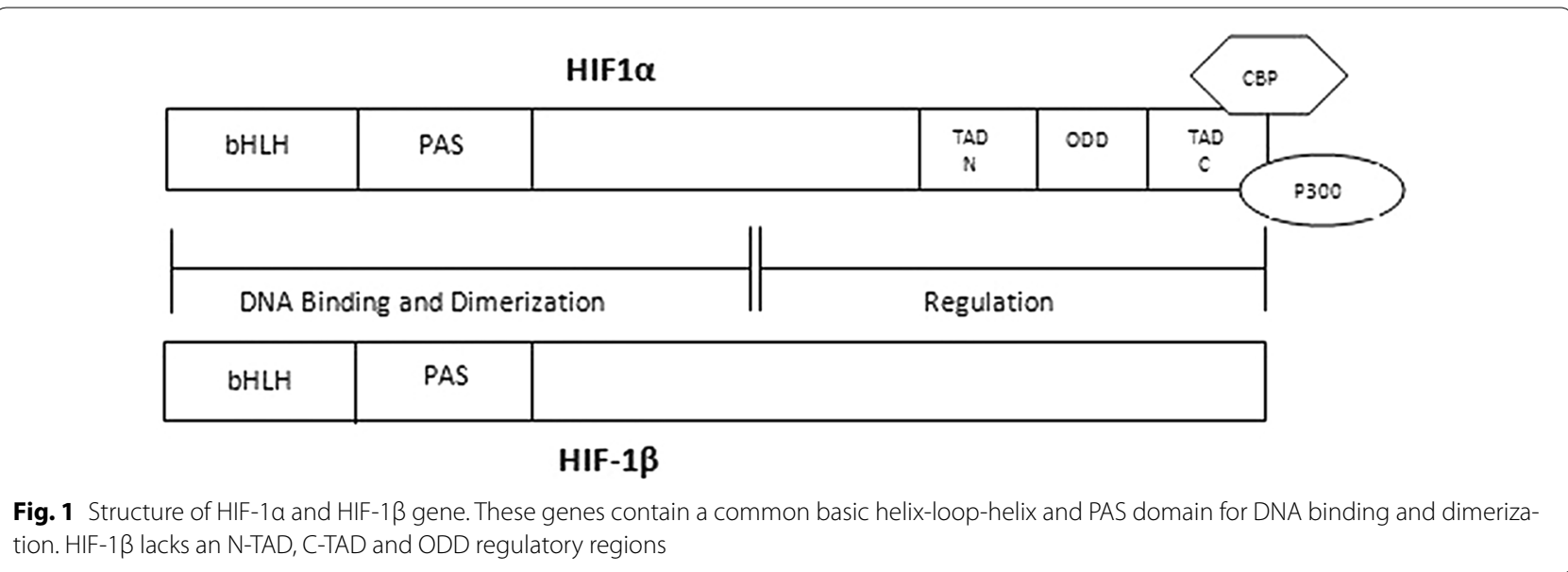


HIF up-regulates the angiogenic growth factors such as vascular endothelial growth factor (VEGF) [18] and epidermal growth factor (EGF) through transcriptional activation. HIF enhances endothelial cell migration towards tissues with low oxygen level. These cells aid to form new blood vessels to overcome oxygen requirement [19]. VEGF enhances the infiltration of macrophages through macrophage receptors (flt-1). These macrophages release more VEGF and tumor necrosis factor- alpha (TNF- $\alpha$ ) indicating positive regulation. HIF-1 also regulates glycolysis which is a vital pathway for energy production. It regulates the uptake of glucose through glucose transporters, i.e. glucose transporter 1 (GLUT1) and sodiumglucose transporters (SGLT) [20]. In absence of oxygen, metabolic pathways shift from more productive oxidative phosphorylation to less efficient anaerobic metabolism for maintenance of ATP production (Warburg effect) [21]. This shift is done through up-regulation of hexokinase, aldolase, pyruvate kinase and down-regulation of pyruvate dehydrogenase which promotes the conversion of pyruvate to acetyl CoA to enter the citric acid cycle [22]. Recently, it has been observed that the embryonic stem cells go through metabolic shift during development towards glycolysis which is regulated by HIF-1 [23].

Tumor cells have acidic extracellular $\mathrm{pH}(6.2-6.8)$ than normal cells (7.2-7.4) [24, 25]. More lactic acid production and poor removal, as well as the production of carbonic acid, are main reasons for this condition. Monocarboxylate transporters (MCT4) upregulates by hypoxic conditions, which secrete more lactic acid from tumor cells [26]. Also, HIF-induced ectoenzyme CA (carbonic anhydrase) IX or XII converts diffused carbon dioxide into carbonic acid to reduce extracellular $\mathrm{pH}$ [27]. Histochemical studies have shown that CA IX and CA XII isoforms expressed highly in tumor cells, which are thus a suggestive diagnostic marker for cancer.

\section{Regulation of HIF-1}

HIF- $1 \alpha$ constitutively expresses independently of oxygen level through various signaling pathways in cancer [28]. Most post-translational modification accounts for HIF- $1 \alpha$ stability and transcriptional activity via ubiquitination, acetylation, sumoylation, hydroxylation, and phosphorylation [28]. There are two types of the pathway which regulate the expression of HIF- $1 \alpha$, oxygen dependent and oxygen independent pathway (Fig. 3).

\section{Oxygen-dependent regulation pVHL dependent pathway}

In normoxic conditions, level of HIF-1 is tightly regulated by von Hippel-Lindau protein ( $\mathrm{pVHL}$ ), a tumor suppressor protein through proteasomal degradation and ubiquitination [29]. Another enzyme called prolyl-4-hydroxylases (PHDs) or HIF-1 prolyl hydroxylases $(\mathrm{HPH})$ also participates in the degradation of HIF-1 $\alpha$. Two proline residues $\left(\mathrm{P}^{402} / \mathrm{P}^{564}\right)$ present on KXXLAP amino acid motif of ODD domain acts as a substrate for PHDs [30, 31]. This degradation requires 2-oxoglutarate (2-OG), oxygen and ascorbate [32]. An enzyme, arrest defective-1 (ARD-1) plays an important role by acetylating lysine $\left(\mathrm{K}^{532}\right)$ residue in the ODD domain [33]. Hypoxic condition inhibits the activity of both the enzymes resulting in up-regulation of HIF- $1 \alpha$ activity. Hypoxia disrupts the electron transport chain, thus accumulating reactive oxygen species (ROS), which in turn oxidizes $\mathrm{Fe}^{2+}$ to $\mathrm{Fe}^{3+}$ resulting in inhibition of PHD activity and stabilization of HIF-1 $\alpha$. Knockdown of transferrin receptor-1 through small hairpin RNA (shRNA) leads to decrease in iron uptake, high HIF expression and extensive angiogenesis in breast cancer cell lines [34]. Antioxidant response from junD in Ki-Ras transformed fibroblast cells have been reported to reduce HIF expression and angiogenesis by enhancing PHDs expression [35]. Both antioxidant $\mathrm{N}$-acetylcysteine and ascorbate abolish HIF activation through increased hydroxylation [36]. These findings propose the involvement of hypoxia and reactive oxygen species in altering HIF expression through various mechanisms. HIF- $1 \alpha$ promoter contains a binding site for necrosis factor-kappa B (NF-кB) which conveys up-regulation by oxidative stress [37]. Transcription of HIF- $1 \beta$ is also regulated directly by NF- $\mathrm{KB}$ [38]. So, it is concluded that PHDs, ARD and VHL all require oxygen to stabilize the HIF- $1 \alpha$ structure.

\section{pVHL independent pathway}

Another regulatory pathway is post-translational modifications of HIF-1 in the presence of oxygen but without the involvement of $\mathrm{pVHL}$ protein. Binding of C-TAD and co-activators $\mathrm{CBP} / \mathrm{p} 300$ are must for transcriptional activation of HIF- $1 \alpha$ target genes. In the presence of oxygen, asparagine residue $\left(\mathrm{N}^{803}\right)$ of HIF- $1 \alpha \mathrm{C}-\mathrm{TAD}$ domain gets hydroxylated by factor inhibiting HIF-1 (FIH-1), an asparagine hydroxyl, hinders the interaction between two domains and results in the down-regulation of HIF- $1 \alpha$ mediated gene transcription [39-42]. Hypoxic conditions hinder hydroxylation of asparagine and hence establish transactivation of HIF-1 $\alpha$ [40-42]. Hence, pVHL dependent pathway stabilizes HIF- $1 \alpha$, while pVHL independent pathway regulates its transactivation.

\section{Calcium-mediated regulation}

Hypoxia-induced accumulation of calcium also promotes the expression of HIF- $1 \alpha$. Various targets of $\mathrm{Ca}^{2+} / \mathrm{CAM}$ such as CAM kinase II, actin and calcineurin increase the transcriptional expression of HIF- $1 \alpha$. Therefore suppression of $\mathrm{Ca}^{2+} / \mathrm{CAM}$ by CAM-dominant mutants, $\mathrm{Ca}^{2+}$ 


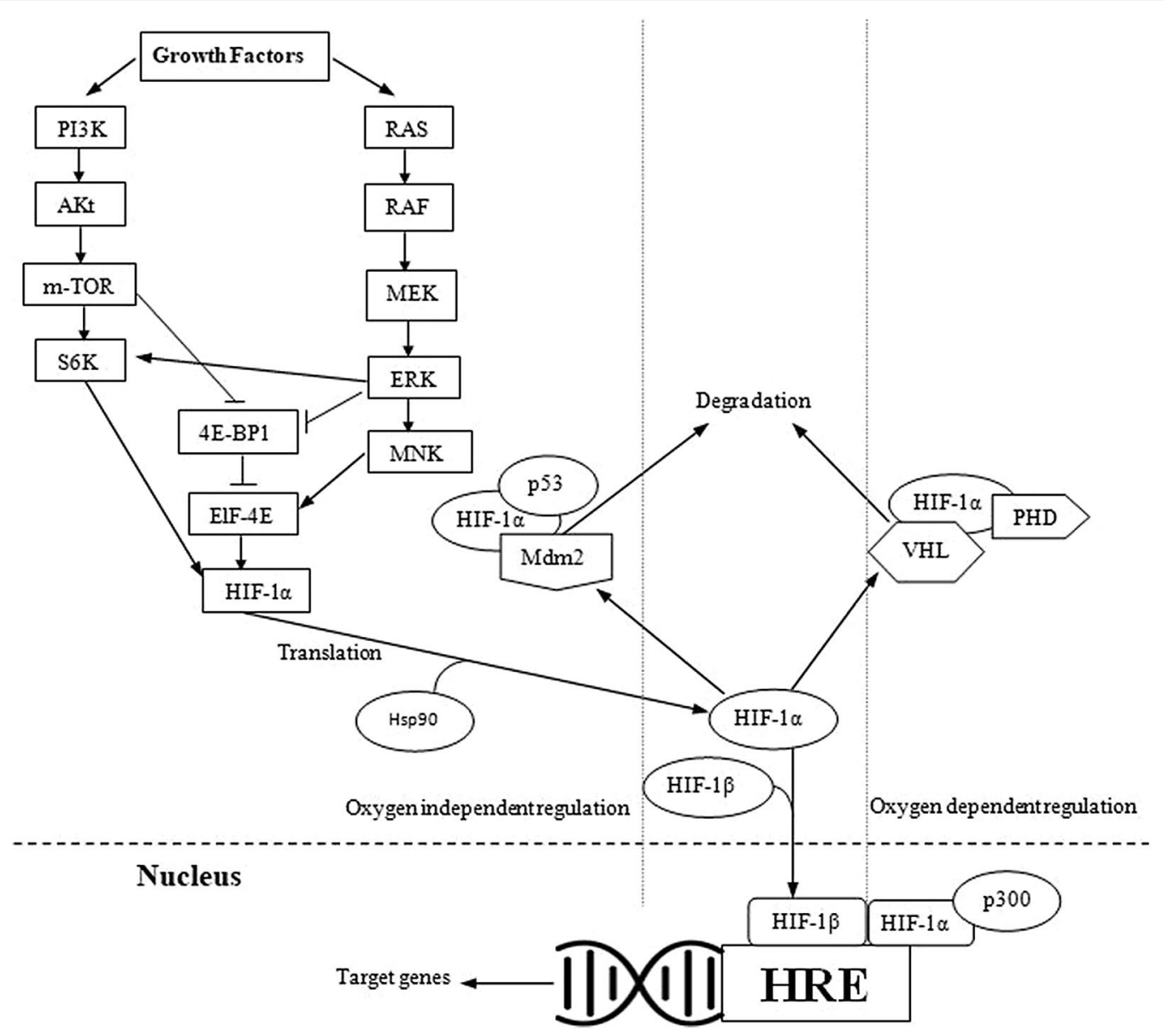

Fig. 3 Oxygen-dependent and independent regulatory pathways of HIF-1

antagonists, i.e. $\mathrm{HBC}$ or $\mathrm{Ca}^{2+}$ chelators reduces transcriptional activity of HIF and thus angiogenesis [43, 44].

\section{Oxygen-independent regulation}

Despite the role of hydroxylases, there are some other oncogenic regulatory pathways which play an important role in oxygen independent regulation of HIF- $1 \alpha$ activity.

\section{Growth factor signaling pathway}

Various growth factors regulate the expression of HIF- $1 \alpha$ through a wide range of signaling cascades, i.e. PI3K/ PTEN/AKT or RAS/RAF/MAPK [45]. Most of them regulate translation of HIF- $1 \alpha$ while some also regulate transcription. Phosphatidylinositol-4,5-bisphosphate 3-kinase (PI3K) regulates the expression of HIF-1 $\alpha$ through its target protein kinase B (AKT) a serine/threonine kinase and further downstream mTOR. mTOR phosphorylates the eukaryotic translation initiation factor $4 \mathrm{E}$ (elF-4E) binding protein (4E-BP). 4E-BP disrupts cap-dependent mRNA translation. mTOR dependent phosphorylation of P70S6K (S6K) enhances the activity of its substrate ribosomal protein $\mathrm{S} 6$ and promotes HIF- $1 \alpha$ translation [46]. The AKT signaling may regulate HIF- $1 \alpha$ expression by both mTOR dependent and independent pathways [47]. This pathway is hindered by PTEN, which dephosphorylates PI3K products [47]. Certain growth factors activate RAS which further stimulates MAPK pathway [48]. This pathway involves RAS/ RAF/MEK/ERK kinase cascade. An activated extracellular signal-regulated kinase (ERK) phosphorylate MAP kinase-interacting kinase (NNK) and S6K to activate them and 4E-BP1 to inactivate it. MNK phosphorylates elF4E protein to enhance HIF-1 $\alpha$ translation [49]. ERK also stimulates transcriptional activation of HIF- $1 \alpha$ by phosphorylating $\mathrm{CBP} / \mathrm{P} 300$ co-activators for enhancing HIF- $1 \alpha /$ co-activators complex formation [50].

\section{Mdm2 pathway}

Mouse double minute 2 homolog (Mdm2) plays an important role along with p53 in cancer. In hypoxic conditions binding of p53 with HIF-1 $\alpha$ enhances its degradation through Mdm2 mediated ubiquitination and 
proteasomal degradation [50]. This degradation occurs in the cytoplasm and controlled by PTEN/PI3K/AKT pathway [51]. Undoubtedly, loss of p53 in the tumor is associated with the enhanced level of HIF-1 $\alpha$ expression [52].

\section{Through HSP9O}

Many other minor pathways play a key role in regulating HIF- $1 \alpha$ level. Heat shock protein 90 (HSP90) is a molecular chaperone which facilitates synthesis and folding of proteins. Direct interaction of HSP90 with HIF- $1 \alpha$ enhances its dimerization with HIF- $1 \beta$ through conformational changes [53]. Geldanamycin, an HSP90 inhibitor enhances HIF- $1 \alpha$ degradation even in cells lacking pVHL [54]. Mutations in $\mathrm{P}^{402} / \mathrm{P}^{534}$ sites of HIF- $1 \alpha$ do not secure it from Geldanamycin-induced degradation.

\section{HIF induced metabolic alterations}

The functional gain of oncogenes and loss of function of tumor suppressor genes are the main characteristic of cancer cells [55]. This causes uncontrolled proliferation to form a solid mass. So in order to maintain energy level for dividing cells, a continuous supply of anabolic building blocks and energy carriers are established. Alterations of metabolic pathways were added to the six cancer hallmarks by Hanahan and Weinberg [55]. These pathways contain up-regulation of glycolysis, mitochondrial biogenesis, lipid and amino acid metabolism, pentose phosphate pathway and macromolecule biosynthesis. Some of them are shown in Fig. 4.

In comparison with normal cells, cancer cells prioritize lactic acid production (anaerobic glycolysis) instead oxidative phosphorylation even in normoxic conditions also known as Warburg effect [56]. In later studies, it was observed that the dividing lymphocytes also use $90 \%$ of their glucose carbon to form lactate, which rules out the probability that anaerobic glycolysis is only associated with cancer cells [57]. HIF-1 and c-Myc are two major regulators of glycolytic enzymes such as hexokinase (HK2), phosphofructokinase (PFK1), triosephosphate isomerase (TPI1) and lactate dehydrogenase (LDHA) [20,
58-60]. At a low level of HIF-1, the end product of glycolysis is converted to acetyl-CoA, which enters into the citric acid cycle. In TCA cycle, high-energy molecules, i.e. FAD and $\mathrm{NADH}$ are generated, which further produce a high number of ATPs through electron transport chain in mitochondria. Normal cells prefer anaerobic glycolysis only in the absence of oxygen. In comparison, cancer cells use only anaerobic glycolysis even in abundance of oxygen [58, 61, 62]. As per the research findings, if glucose influx is high enough, only then the percentage of ATP generated from glycolysis goes above that produced from oxidative phosphorylation [63]. Pyruvate kinase an enzyme which converts phosphoenolpyruvate to pyruvate was recently reported as a regulator of Warburg effect [64].

Another glycolytic enzyme responsible for regulatory metabolic pathways at enhanced HIF- $1 \alpha$ expression is pyruvate kinase (PK). It encodes by two genes, PKLR and PKM2. PKM2 gene codes for two alternatively spliced transcripts, PKM1 and PKM2. PKM1 is primarily restricted to brain and muscles while PKM2 to fast proliferating cells like cancer $[65,66]$. Some glucose depleted cell cultures have been shown to stabilize HIF- $1 \alpha$ by inhibiting PHDs through Pyruvate formed from lactate by lactate dehydrogenase [67]. Accumulation of lactate $(10 \mathrm{mM})$ in cancer has been suggested to activate HIF-1 and VEGF [68]. Pyruvate and oxaloacetate inactivate the PHDs, reversal of which requires ascorbate [69]. Thus there are at least two mechanisms to inactivate HIF hydroxylases, one is competition with 2-OG and second by oxidation.

TCA cycle is the second pathway after glycolysis in the metabolism of glucose. Pyruvate, the end product of glycolysis enter TCA cycle only via production of acetylCoA. HIF- $1 \alpha$ mediated upregulation of pyruvate dehydrogenase kinase reduce acetyl-CoA production through inactivation of pyruvate dehydrogenase enzyme by phosphorylation [70]. Production of NADH by conversion of lactate from pyruvate with the help of lactate dehydrogenase accelerates glycolysis [71]. Another benefit taken

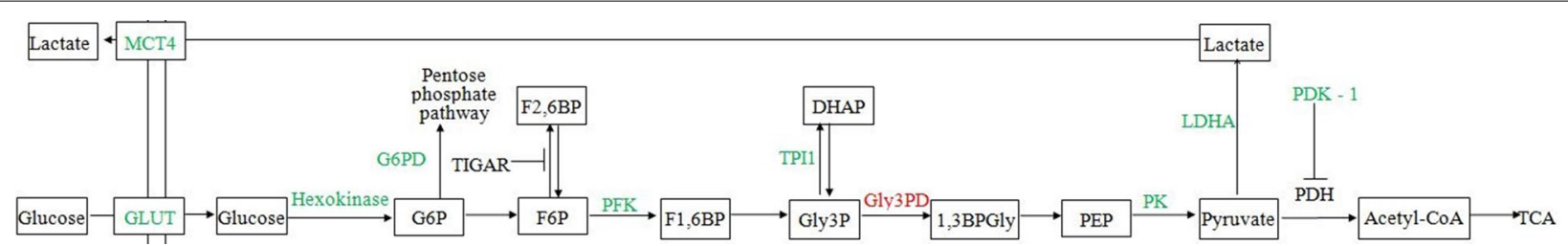

Fig. 4 Metabolic targets of HIF-1 in cancer cells. GLUT: glucose transporter; G6P: glucose 6-phosphate; G6PD: glucose 6-phosphate dehydrogenase; F6P: fructose 6-phosphate; F2,6BP: fructose 2,6-bisphosphate; PFK: phosphofructokinase; F1,6BP: fructose 2,6-bisphosphate; Gly3P: glyceraldehyde 3-phosphate; TPI1: triosphosphate isomerase1; DHAP: dihydroxyacetone phosphate; Gly3PD: glyceraldehyde 3-phosphate dehydrogenase; 1,3BPGly: 1,3-bisphosphoglycerate; PEP: phosphoenol pyruvate; PK: pyruvate kinase; LDHA: lactate dehydrogenase; PDH: pyruvate dehydrogenase; PDK1: pyruvate dehydrogenase kinase-1 
by cancer cells from enhanced production of lactate is that they secrete it in tumor microenvironment through MCT4 transporters to other cancer cells, who have not sufficient fuel supply, so to feed them energy.

Pentose phosphate pathway (PPP) is a major pathway for nucleotide biosynthesis through ribose 5-phosphate (R5P) intermediate. p53 plays a major role in controlling both the oxidative and non-oxidative arms of PPP pathway. TP53-induced glycolysis and apoptosis regulator (TIGAR), a target of p53 regulate glycolysis by suppressing the expression of phosphofructokinase- 1 and by increasing substrate delivery to citric acid pathway [72]. Cancer cells lacking or mutated p53 lose their control to regulate PPP pathway and hence increases in glycolytic efflux. Glyceraldehyde-3-phosphate dehydrogenase (GAPDH) plays a major role in the regulation of this pathway. Suppressive oxidative phosphorylation reduces $\mathrm{NAD}^{+} / \mathrm{NADH}$ ratio and hence GAPDH activity. Hence down-regulated GAPDH expression creates a boundary for lower glycolytic pathways, creating a high pressure of upper glycolytic substrates, which then enhance reversible non-oxidative PPP pathway for nucleotide biosynthesis [73]. Glucose 6-phosphate dehydrogenase (G6PD) is another important enzyme of PPP pathway which promotes cancer formation by providing NADH [74]. P53 tightly regulate this enzyme by preventing its active dimerization [75]. G6PD is a direct target of HIF-1 to transactivate it [76]. Surprisingly, G6PD and VEGF crosstalk in cancer cells and are highly associated with angiogenesis $[77,78]$.

Catabolism of glutamine is another key metabolic pathway for cancer cells. End products of glutaminolysis serve as intermediates for TCA cycle. Like glycolysis, glutaminolysis provides not only ATP but also some crucial precursors for cell proliferation [79-81]. C-Myc transactivates alanine-serine-cysteine (ASCT2) and system N (SN2) transporters for glutamine and up-regulates glutaminase (GLS1) expression [82]. The high rate of lactate and alanine excretion per mole of glutamine, like the evident insufficiency of Warburg effect, has been seen in proliferating cells $[78,83]$. Rather than regular discernment that normal cells use glutamine as a nitrogen source, glutamine digestion in tumor cells bring high intracellular nitrogen that must be discharged as alanine or ammonia. Glutaminase enzyme removes its amido group as ammonia. In glioblastoma cells, a large part of glutamine's amino groups was likewise lost in $\alpha$-ketoglutarate $(\alpha-K G)$ producing reactions (glutamate dehydrogenase and alanine aminotransferase) [84]. In this way, usage of glutamine as an anaplerotic precursor and source of NADPH results in the discharge of large fraction of glutamine-derived carbon and nitrogen. A portion of secreted molecules may, therefore, be utilized as precursors for hepatic gluconeogenesis, hence giving more fuel for tumor digestion. At first look, these seem, by all accounts, to be side effects of metabolic inefficiency. However, they may actually give a logical and specialized metabolism that empower cell growth and metabolism. In this way, HIF-1 $\alpha$ alter a number of metabolic pathways that play their role in cancer by providing energy to the cell for proliferation, growth, and survival. Targeting specific substrates of these pathways may help to control cancer progression.

\section{Conclusions}

Both HIF-1 and metabolic pathways participate in cancer progression by giving an enhanced supply of energy (metabolic pathways) and sufficient oxygen (HIF-1). A sequence of signaling cascades is involved by these two factors to survive cancer cells through the harsh environment and immune surveillance. Both the pathways are up-regulated in cancer. Warburg effect, which is a characteristic of altered glycolytic pathways in cancer, is also seen in dividing lymphocytes and embryonic stem cells. HIF-1, a mark of the hypoxic condition is also seemed to be regulated in an oxygen-independent manner. This complex regulation contributes to the propagation of cancer through multiple pathways.

\section{Future perspectives}

The involvement of HIF in cancer progression directs our intention to discover anticancer drugs which inhibit HIF-1 expression directly or indirectly by regulating HIF- $1 \alpha$ mRNA, HIF-1 $\alpha$ protein translation, HIF- $1 \alpha$ protein degradation, HIF- $1 \alpha$ and HIF- $1 \beta$ subunit interactions and HIF- $1 \alpha$ DNA binding activity. Numerous studies focused on cancer, entail discovery of drugs which are synthetic in nature. A number of studies are reported to compile mode of action of these anticancer drugs in contrast with the HIF-1 regulation [20, 85-91]. However, even after extensive research, there is a gap to target cancer with a single molecule because of multiple survival pathways, different infected organs and huge side effects of synthetic drugs. From last decade, researchers have identified some natural plant compounds, i.e. vinca alkaloids, taxanes, camptothecins [92] which have fewer side effects than synthetic ones. Recently, a new natural compound sulforaphane was identified, which eliminates cancer stem cells in many cancer types [93-95]. Multiple survival pathways make trouble for anticancer drug discovery. Some substrates which are common for multiple responsible pathways for cancer may help to target it with a novel universal drug in future. This requires extensive study of signaling cascades and its regulation on each step. 


\begin{abstract}
Abbreviations
HIF-1: hypoxia-inducible factor; ROS: reactive oxygen species; ARNT: aryl hydrocarbon receptor nuclear translocator; AhR: aryl hydrocarbon receptor; bHLH: basic helix loop helix; PAS: Per ARNT Sim; ODD: oxygen-dependent domain; N-TAD: N-terminal transactivational domain; C-TAD: C-terminal transactivational domain; CBP: C-TAD binding protein; KAT: Iycin acetyl transferase; DNA: deoxyribonucleic acid; VEGF: vascular endothelial growth factor; EGF: epidermal growth factor; TNF-a: tumor necrosis factor-a; GLUT1: glucose transporter 1; SGLT: sodium-glucose transporter; ATP: adenosine triphosphate: MCT-4: monocarboxylate transporter-4; CA: carbonic anhydrase; VHL: von Hippel-Lindau; PHDs: prolyl-4-hydroxylases; HPH: HIF-1 prolyl hydroxylase; 2-OG: 2-oxoglutarate; ARD-1: arrest defective-1; shRNA: small hairpin ribonucleic acid; NF-KB: necrosis factor-kappa B; FIH-1: factor inhibiting HIF-1; PI3K: phosphatidyl inositol-4,5-bisphosphate 3-kinase; $\mathrm{m}$-TOR: mammalian target of rapamycin; elF-4E: eukaryotic translation initiation factor-4E; 4EBP: elF-4E binding protein; PTEN: phosphatase and tensin homolog; MAPK: mitogenactivated protein kinase; ERK: extracellular signal-regulated kinase; MNK: MAP kinase-interacting kinase; Mdm2: mouse double minute 2 homolog; HSP90: heat shock protein 90; CAM: calmodulin-dependent kinase; HK2: hexokinase 2; PFK1: phosphofructokinase 1; TPI1: triphosphate isomerase 1; LDHA: lactate dehydrogenase; TCA: tricarboxylic acid; FAD: flavin adenine dinucleotide; NADH: nicotinamide adenine dinucleotide; PPP: pentose phosphate pathway; R5P: ribose 5-phosphate; TIGAR: TP-53-induced glycolysis and apoptosis regulator; GAPD: glyceraldehyde-phosphate dehydrogenase; G6PD: glucose 6-phosphate dehydrogenase; PK: pyruvate kinase; ASCT: alanine, serine, cysteine transporter 2; SN2: system n-2 transporter; GLS1: glutaminase 1; aKG: a-ketoglutarate; mRNA: messenger ribonucleic acid.
\end{abstract}

\section{Authors' contributions}

$D S, R A$, and PK collected the data and wrote the manuscript. BS and RM helped in the correction of the manuscript. Corresponding author SA conceived the idea, analyzed the data and helped in the correction of the manuscript. All authors read and approved the final manuscript.

\section{Author details \\ ${ }^{1}$ Department of Botanical and Environmental Sciences, Guru Nanak Dev University, Amritsar 143005, India. ${ }^{2}$ Department of Biochemistry, Sri Guru Ram Das University of Health Sciences, Amritsar 143001, India. ${ }^{3}$ Department of Pharmaceutical Sciences, Guru Nanak Dev University, Amritsar 143005, India. ${ }^{4}$ Department of Pathology, Sri Guru Ram Das University of Health Sci- ences, Amritsar 143001, India.}

\section{Acknowledgements}

Not applicable.

\section{Competing interests}

The authors declare that they have no competing interests.

Availability of data and materials

All data are fully available without restrictions.

\section{Consent for publication}

All authors reviewed the manuscript and consent for publication.

\section{Ethics approval and consent to participate}

Not applicable.

\section{Funding}

Not applicable.

\section{Publisher's Note}

Springer Nature remains neutral with regard to jurisdictional claims in published maps and institutional affiliations.

Received: 14 July 2017 Accepted: 6 November 2017

Published online: 13 November 2017
References

1. World Health Organization. Fact sheet no 297. 2017. http://www.who.int/ mediacentre/factsheets/fs297/en/index.html. Accessed 19 Jun 2017.

2. Masson N, Ratcliffe PJ. Hypoxia signaling pathways in cancer metabolism: the importance of co-selecting interconnected physiological pathways. Cancer Metab. 2014;2:1-3.

3. Hockel M, Vaupel P. Tumor hypoxia: definitions and current clinical, biologic, and molecular aspects. J Natl Cancer Inst. 2001;93:266-76.

4. Chen L, Shi Y, Yuan J, Han Y, Qin R, Wu Q, et al. HIF-1 alpha overexpression correlates with poor overall survival and disease-free survival in gastric cancer patients post-gastrectomy. PLoS ONE. 2014;9:e90678.

5. Baba Y, Nosho K, Shima K, Irahara N, Chan AT, Meyerhardt JA, et al. HIF-1a overexpression is associated with poor prognosis in a cohort of 731 colorectal cancers. Am J Pathol. 2010;176:2292-301.

6. Semenza GL. HIF-1 mediates metabolic responses to intratumoral hypoxia and oncogenic mutations. J Clin Investig. 2013;123:3664-71.

7. Kurokawa T, Miyamoto M, Kato K, Cho Y, Kawarada Y, Hida Y, et al. Overexpression of hypoxia-inducible-factor 1 a (HIF-1a) in oesophageal squamous cell carcinoma correlates with lymph node metastasis and pathologic stage. Br J Cancer. 2003;89:1042-7.

8. Zhou J, Huang S, Wang L, Yuan X, Dong Q, Zhang D, et al. Clinical and prognostic significance of HIF-1a overexpression in oral squamous cell carcinoma: a meta-analysis. World J Surg Oncol. 2017;15:104.

9. Ema M, Taya S, Yokotani N, Sogawa K, Matsuda Y, Fujii-Kuriyama Y. A novel bHLH-PAS factor with close sequence similarity to hypoxiainducible factor 1 a regulates the VEGF expression and is potentially involved in lung and vascular development. Proc Natl Acad Sci. 1997;94:4273-8.

10. Gu YZ, Moran SM, Hogenesch JB, Wartman L, Bradfield CA. Molecular characterization and chromosomal localization of a third a-class hypoxia inducible factor subunit, HIF-3a. Gene Expr. 1998;7:205-13.

11. Tian H, McKnight SL, Russell DW. Endothelial PAS domain protein 1 (EPAS1), a transcription factor selectively expressed in endothelial cells. Genes Dev. 1997;11:72-82.

12. Wang GL, Jiang BH, Rue EA, Semenza GL. Hypoxia-inducible factor 1 is a basic-helix-loop-helix-PAS heterodimer regulated by cellular $\mathrm{O}_{2}$ tension. Proc Natl Acad Sci. 1995;92:5510-4.

13. Jiang BH, Rue E, Wang GL, Roe R, Semenza GL. Dimerization, DNA binding, and transactivation properties of hypoxia-inducible factor 1. J Biol Chem. 1996;271:17771-8.

14. Pugh CW, O'Rourke JF, Nagao M, Gleadle JM, Ratcliffe PJ. Activation of hypoxia-inducible factor-1; definition of regulatory domains within the a subunit. J Biol Chem. 1997;272:11205-14.

15. Ivan M, Kondo K, Yang H, Kim W, Valiando J, Ohh M, et al. HIFa targeted for VHL-mediated destruction by proline hydroxylation: implications for $\mathrm{O}_{2}$ sensing. Science. 2001;292:464-8.

16. Bedford DC, Kasper LH, Fukuyama T, Brindle PK. Target gene context influences the transcriptional requirement for the KAT3 family of CBP and p300 histone acetyltransferases. Epigenetics. 2010;5:9-15.

17. Semenza GL. HIF-1 and human disease: one highly involved factor. Genes Dev. 2000;14:1983-91.

18. Ziello JE, Jovin IS, Huang Y. Hypoxia-Inducible Factor (HIF)-1 regulatory pathway and its potential for therapeutic intervention in malignancy and ischemia. Yale J Biol Med. 2007;80:51-60.

19. Richard DE, Berra E, Pouysségur J. Nonhypoxic pathway mediates the induction of hypoxia-inducible factor 1 a in vascular smooth muscle cells. J Biol Chem. 2000;275:26765-71.

20. Denko NC. Hypoxia, HIF1 and glucose metabolism in the solid tumour. Nat Rev Cancer. 2008;8:705-13.

21. Burk D, Schade AL. On respiratory impairment in cancer cells. Science (New York, NY). 1956;124:270.

22. Semenza GL, Roth PH, Fang HM, Wang GL. Transcriptional regulation of genes encoding glycolytic enzymes by hypoxia-inducible factor 1. J Biol Chem. 1994;269:23757-63.

23. Zhou W, Choi M, Margineantu D, Margaretha L, Hesson J, Cavanaugh C, et al. HIF1a induced switch from bivalent to exclusively glycolytic metabolism during ESC-to-EpiSC/hESC transition. EMBO J. 2012;31:2103-16.

24. Harguindey S, Orive G, Pedraz JL, Paradiso A, Reshkin SJ. The role of $\mathrm{pH}$ dynamics and the $\mathrm{Na}^{+} / \mathrm{H}^{+}$antiporter in the etiopathogenesis and treatment of cancer. Two faces of the same coin-one single nature. Biochimica et Biophysica Acta (BBA) Rev Cancer. 2005;1756:1-24. 
25. Gerweck LE, Vijayappa S, Kozin S. Tumor pH controls the in vivo efficacy of weak acid and base chemotherapeutics. Mol Cancer Ther. 2006;5:1275-9.

26. Ullah MS, Davies AJ, Halestrap AP. The plasma membrane lactate transporter MCT4, but not MCT1, is up-regulated by hypoxia through a HIF-1a-dependent mechanism. J Biol Chem. 2006;281:9030-7.

27. Švastová E, Hulíková A, Rafajová M, Zat'ovičová M, Gibadulinová A, Casini A, et al. Hypoxia activates the capacity of tumor-associated carbonic anhydrase IX to acidify extracellular pH. FEBS Lett. 2004;577:439-45.

28. Kallio PJ, Pongratz I, Gradin K, McGuire J, Poellinger L. Activation of hypoxia-inducible factor $1 \mathrm{a}$ : posttranscriptional regulation and conformational change by recruitment of the Arnt transcription factor. Proc Natl Acad Sci. 1997;94:5667-72.

29. Iwai K, Yamanaka K, Kamura T, Minato N, Conaway RC, Conaway JW, et al. Identification of the von Hippel-Lindau tumor-suppressor protein as part of an active E3 ubiquitin ligase complex. Proc Natl Acad Sci. 1999;96:12436-41.

30. Bruick RK, McKnight SL. A conserved family of prolyl-4-hydroxylases that modify HIF. Science. 2001:294:1337-40.

31. Epstein AC, Gleadle JM, MCNeill LA, Hewitson KS, O'Rourke J, Mole DR, et al. C. elegans EGL-9 and mammalian homologs define a family of dioxygenases that regulate HIF by prolyl hydroxylation. Cell. 2001;107:43-54.

32. Jaakkola P, Mole DR, Tian YM, Wilson MI, Gielbert J, Gaskell SJ, et al. Targeting of HIF-a to the von Hippel-Lindau ubiquitylation complex by $\mathrm{O}_{2}$-regulated prolyl hydroxylation. Science. 2001;292:468-72.

33. Jeong JW, Bae MK, Ahn MY, Kim SH, Sohn TK, Bae MH, et al. Regulation and destabilization of HIF-1a by ARD1-mediated acetylation. Cell. 2002:111:709-20.

34. Eckard J, Dai J, Wu J, Jian J, Yang Q, Chen H, et al. Effects of cellular iron deficiency on the formation of vascular endothelial growth factor and angiogenesis. Cancer Cell Int. 2010;10:28

35. Gerald D, Berra E, Frapart YM, Chan DA, Giaccia AJ, Mansuy D, et al. JunD reduces tumor angiogenesis by protecting cells from oxidative stress. Cell. 2004;118:781-94.

36. Gao P, Zhang H, Dinavahi R, Li F, Xiang Y, Raman V, et al. HIF-dependent antitumorigenic effect of antioxidants in vivo. Cancer Cell. 2007;12:230-8.

37. Bonello S, Zähringer C, BelAiba RS, Djordjevic T, Hess J, Michiels C, et al. Reactive oxygen species activate the HIF-1 a promoter via a functional NFkB site. Arterioscler Thromb Vasc Biol. 2007;27:755-61.

38. Van Uden P, Kenneth NS, Webster R, Müller HA, Mudie S, Rocha S. Evolutionary conserved regulation of HIF-1 $\beta$ by NF-KB. PLOS Genet. 2011;7:e1001285.

39. Block KM, Wang H, Szabó LZ, Polaske NW, Henchey LK, Dubey R, et al. Direct inhibition of hypoxia-inducible transcription factor complex with designed dimeric epidithiodiketopiperazine. J Am Chem Soc. 2009;131:18078-88.

40. Dann CE, Bruick RK, Deisenhofer J. Structure of factor-inhibiting hypoxiainducible factor 1: an asparaginyl hydroxylase involved in the hypoxic response pathway. Proc Natl Acad Sci. 2002;99:15351-6.

41. Lando D, Peet DJ, Gorman JJ, Whelan DA, Whitelaw ML, Bruick RK. FIH-1 is an asparaginyl hydroxylase enzyme that regulates the transcriptional activity of hypoxia-inducible factor. Genes Dev. 2002;16:1466-71.

42. McNeill LA, Hewitson KS, Claridge TD, Seibel JF, Horsfall LE, Schofield CJ. Hypoxia-inducible factor asparaginyl hydroxylase $(\mathrm{FlH}-1)$ catalyses hydroxylation at the $\beta$-carbon of asparagine-803. Biochem J. 2002:367:571-5.

43. Kwon HJ. Discovery of new small molecules and targets towards angiogenesis via chemical genomics approach. Curr Drug Targets. 2006;7:397-405

44. Jung HJ, Kim JH, Shim JS, Kwon HJ. A novel $\mathrm{Ca}^{2+} /$ calmodulin antagonist $\mathrm{HBC}$ inhibits angiogenesis and down-regulates hypoxia-inducible factor. J Biol Chem. 2010;285:25867-74.

45. Pouysségur J, Dayan F, Mazure NM. Hypoxia signalling in cancer and approaches to enforce tumour regression. Nature. 2006;441:437-43.

46. Gingras AC, Raught B, Sonenberg N. Regulation of translation initiation by FRAP/mTOR. Genes Dev. 2001;15:807-26.

47. Pore N, Jiang Z, Shu HK, Bernhard E, Kao GD, Maity A. Akt1 Activation can augment hypoxia-inducible factor-1 a expression by increasing protein translation through a mammalian target of rapamycin-independent pathway. Mol Cancer Res. 2006;4:471-9.

48. Semenza GL. Signal transduction to hypoxia-inducible factor 1. Biochem Pharmacol. 2002;64:993-8.
49. Sang N, StiehI DP, Bohensky J, Leshchinsky I, Srinivas V, Caro J. MAPK signaling up-regulates the activity of hypoxia-inducible factors by its effects on p300. J Biol Chem. 2003;278:14013-9.

50. Ravi R, Mookerjee B, Bhujwalla ZM, Sutter CH, Artemov D, Zeng Q, et al. Regulation of tumor angiogenesis by p53-induced degradation of hypoxia-inducible factor 1a. Genes Dev. 2000;14:34-44.

51. Joshi S, Singh AR, Durden DL. MDM2 regulates hypoxic hypoxia-inducible factor 1a stability in an E3 ligase, proteasome, and PTEN-phosphatidylinositol 3-kinase-AKT-dependent manner. J Biol Chem. 2014;289:22785-97.

52. Bae MK, Ahn MY, Jeong JW, Bae MH, Lee YM, Bae SK, et al. Jab1 interacts directly with HIF-1 $a$ and regulates its stability. J Biol Chem. 2002;277:9-12.

53. Gradin K, McGuire J, Wenger RH, Kvietikova I, Toftgård R, Tora L, et al. Functional interference between hypoxia and dioxin signal transduction pathways: competition for recruitment of the Arnt transcription factor. Mol Cell Biol. 1996;16:5221-31.

54. Isaacs JS, Jung YJ, Mimnaugh EG, Martinez A, Cuttitta F, Neckers LM. Hsp90 regulates a von Hippel Lindau-independent hypoxia-inducible factor-1a-degradative pathway. J Biol Chem. 2002;277:29936-44.

55. Hanahan D, Weinberg RA. Hallmarks of cancer: the next generation. Cell. 2011;144:646-74.

56. Warburg O. On the origin of cancer cells. Science. 1956;123:309-14.

57. Warburg O. On respiratory impairment in cancer cells. Science. 1956;124:269-70.

58. DeBerardinis RJ, Lum JJ, Hatzivassiliou G, Thompson CB. The biology of cancer: metabolic reprogramming fuels cell growth and proliferation. Cell Metab. 2008;7:11-20

59. DeBerardinis RJ, Sayed N, Ditsworth D, Thompson CB. Brick by brick: metabolism and tumor cell growth. Curr Opin Genet Dev. 2008;18:54-61.

60. Dang CV, Lewis BC, Dolde C, Dang G, Shim H. Oncogenes in tumor metabolism, tumorigenesis, and apoptosis. J Bioenergy Biomembr. 1997:29:345-54.

61. Yeung SJ, Pan J, Lee MH. Roles of p53, MYC and HIF-1 in regulating glycolysis - the seventh hallmark of cancer. Cell Mol Life Sci. 2008;65:3981-99.

62. Vander Heiden MG, Cantley LC, Thompson CB. Understanding the Warburg effect: the metabolic requirements of cell proliferation. Science. 2009;324:1029-33.

63. Guppy M, Greiner E, Brand K. The role of the Crabtree effect and an endogenous fuel in the energy metabolism of resting and proliferating thymocytes. Eur J Biochem. 1993;212:95-9.

64. Christofk HR, Vander Heiden MG, Harris MH, Ramanathan A, Gerszten $\mathrm{RE}$, Wei R, et al. The M2 splice isoform of pyruvate kinase is important for cancer metabolism and tumour growth. Nature. 2008:452:230-3.

65. Netzker R, Greiner E, Eigenbrodt E, Noguchi T, Tanaka T, Brand K. Cell cycle-associated expression of M2-type isozyme of pyruvate kinase in proliferating rat thymocytes. J Biol Chem. 1992;267:6421-4.

66. Altenberg BA, Greulich KO. Genes of glycolysis are ubiquitously overexpressed in 24 cancer classes. Genomics. 2004;84:1014-20.

67. Sonveaux P, Copetti T, De Saedeleer CJ, Végran F, Verrax J, Kennedy KM, et al. Targeting the lactate transporter MCT1 in endothelial cells inhibits lactate-induced HIF-1 activation and tumor angiogenesis. PLOS ONE. 2012; 7:e33418.

68. Hunt TK, Aslam RS, Beckert S, Wagner S, Ghani QP, Hussain MZ, et al. Aerobically derived lactate stimulates revascularization and tissue repair via redox mechanisms. Antioxid Redox Signal. 2007;9:1115-24.

69. Lu H, Dalgard CL, Mohyeldin A, McFate T, Tait AS, Verma A. Reversible inactivation of HIF-1 prolyl hydroxylases allows cell metabolism to control basal HIF-1. J Biol Chem. 2005;280:41928-39.

70. Koukourakis MI, Giatromanolaki A, Sivridis E, Gatter KC, Harris AL, Tumor and Angiogenesis Research Group. Pyruvate dehydrogenase and pyruvate dehydrogenase kinase expression in non small cell lung cancer and tumor-associated stroma. Neoplasia. 2005;7:1-6.

71. Dang CV, Lewis BC, Dolde C, Dang G, Shim H. Oncogenes in tumor metabolism, tumorigenesis, and apoptosis. J Bioenerg Biomembr. 1997:29:345-54

72. Bensaad K, Tsuruta A, Selak MA, Vidal MNC, Nakano K, Bartrons R, et al TIGAR, a p53-inducible regulator of glycolysis and apoptosis. Cell. 2006;126:107-20.

73. Dong W, Keibler MA, Stephanopoulos G. Review of metabolic pathways activated in cancer cells as determined through isotopic labeling and network analysis. Metab Eng. 2017. https://doi.org/10.1016/j. ymben.2017.02.002. 
74. Riganti C, Gazzano E, Polimeni M, Aldieri E, Ghigo D. The pentose phosphate pathway: an antioxidant defense and a crossroad in tumor cell fate Free Radic Biol Med. 2012;53:421-36.

75. Jiang P, Du W, Wang X, Mancuso A, Gao X, Wu M, Yang X. p53 regulates biosynthesis through direct inactivation of glucose-6-phosphate dehydrogenase. Nat Cell Biol. 2011;13:310.

76. Gao L, Mejías R, Echevarría M, López-Barneo J. Induction of the glucose6-phosphate dehydrogenase gene expression by chronic hypoxia in PC12 cells. FEBS Lett. 2004;569:256-60.

77. Pan S, Kovacs CJ, Berk BC. Glucose 6-phosphate dehydrogenase is regulated through c-Src-mediated tyrosine phosphorylation in endothelial cells. Arterioscler Thromb Vasc Biol. 2009;29:895-901.

78. Brand K. Glutamine and glucose metabolism during thymocyte proliferation. Pathways of glutamine and glutamate metabolism. Biochem J. 1985;228:353-61.

79. Dang CV. Glutaminolysis: supplying carbon or nitrogen or both for cancer cells? Cell Cycle. 2010;9:3884-6.

80. Dang CV, Semenza GL. Oncogenic alterations of metabolism. Trends Biochem Sci. 1999;24:68-72.

81. Dang CV, Le A, Gao P. MYC-induced cancer cell energy metabolism and therapeutic opportunities. Clin Cancer Res. 2009;15:6479-83.

82. Gangrade A, Calin GA. MicroRNAs and cancer hallmarks. Cancer Hallm. 2013;1:50-7.

83. Reitzer LJ, Wice BM, Kennell D. Evidence that glutamine, not sugar, is the major energy source for cultured HeLa cells. J Biol Chem. 1979;254:2669-76.

84. DeBerardinis RJ, Mancuso A, Daikhin E, Nissim I, Yudkoff M, Wehrli S, Thompson CB. Beyond aerobic glycolysis: transformed cells can engage in glutamine metabolism that exceeds the requirement for protein and nucleotide synthesis. Proc Natl Acad Sci. 2007;104:19345-50.
85. Giaccia A, Siim BG, Johnson RS. HIF-1 as a target for drug development. Nat Rev Drug Discov. 2003;2:803-11.

86. Melillo G. Targeting hypoxia cell signaling for cancer therapy. Cancer Metastasis Rev. 2007;26:341-52.

87. Ban HS, Uto Y, Nakamura H. Hypoxia-inducible factor inhibitors: a survey of recent patented compounds (2004-2010). Expert Opin Ther Pat. 2011:21:131-46.

88. Onnis B, Rapisarda A, Melillo G. Development of HIF-1 inhibitors for cancer therapy. J Cell Mol Med. 2009;13:2780-6.

89. Wang RB, Zhou SS, Li SS. Cancer therapeutic agents targeting hypoxiainducible factor-1. Curr Med Chem. 2011;18:3168-89.

90. Semenza GL. Targeting HIF-1 for cancer therapy. Nat Rev Cancer. 2003;3:721-32

91. Harris AL. Hypoxia - a key regulatory factor in tumour growth. Nat Rev Cancer. 2002;2:38-47.

92. Kinghorn AD, Chin YW, Swanson SM. Discovery of natural product anticancer agents from biodiverse organisms. Curr Opin Drug Discov Devel. 2009;12:189.

93. Li Y, Zhang T. Targeting cancer stem cells with sulforaphane, a dietary component from broccoli and broccoli sprouts. Future Oncol. 2013;9:1097-103

94. Li Y, Zhang T, Korkaya H, Liu S, Lee HF, Newman B, et al. Sulforaphane, a dietary component of broccoli/broccoli sprouts, inhibits breast cancer stem cells. Clin Cancer Res. 2010;16:2580-90.

95. Sun L, Burnett J, Gasparyan M, Xu F, Jiang H, Lin CC, et al. Novel cancer stem cell targets during epithelial to mesenchymal transition in PTEN-deficient trastuzumab-resistant breast cancer. Oncotarget. 2016;7:51408-22

\section{Submit your next manuscript to BioMed Central and we will help you at every step:}

- We accept pre-submission inquiries

- Our selector tool helps you to find the most relevant journal

- We provide round the clock customer support

- Convenient online submission

- Thorough peer review

- Inclusion in PubMed and all major indexing services

- Maximum visibility for your research

Submit your manuscript at www.biomedcentral com/submit 